\title{
Effectiveness of hermetic containers in controlling paddy rice (Oryza sativa L.) storage insect pests
}

\author{
Gervâncio Covele a, Anacleto Gulube a , Lucas Tivana a, Ana I. Ribeiro-Barros ${ }^{\text {b, c }}$, \\ Maria Otilia Carvalho ${ }^{b}$, Alexis Ndayiragije ${ }^{\mathrm{d}}$, Rafael Nguenha ${ }^{\mathrm{a},{ }^{*}}$ \\ ${ }^{a}$ Universidade Eduardo Mondlane (UEM), Faculdade de Agronomia e Engenharia Florestal, Campus Universitário Principal, Av. Julius Nyerere, 3453, \\ Maputo, Mozambique \\ ${ }^{\mathrm{b}}$ Universidade de Lisboa, Instituto Superior de Agronomia, CEF - Forest Research Center (AIRB) and LEAF-Linking Landscape, Environment, Agriculture and \\ Food (MOC), Tapada da Ajuda, 1349-017, Lisboa, Portugal \\ ${ }^{c}$ GeoBioTec, Faculdade de Ciências e Tecnologia (FCT), Universidade NOVA de Lisboa (UNL), 2829-516, Monte de Caparica, Portugal \\ ${ }^{\mathrm{d}}$ International Rice Research Institute (IRRI), Campus IIAM, Av. das FPLM, Maputo, Mozambique
}

\section{A R T I C L E I N F O}

\section{Article history:}

Received 26 March 2020

Received in revised form 28 August 2020

Accepted 29 August 2020

Available online 10 September 2020

\section{Keywords:}

Damaged grain

Hermetic

Insect infestation

Postharvest losses

Stored rice

\begin{abstract}
A B S T R A C T
Naturally infested paddy rice was used to compare the effectiveness of polypropylene bags and hermetic storage containers over 12 months of storage in a warehouse. Insect pest identification as well as the infestation level, percentage of damaged grain, weight loss, and moisture content were evaluated. Five insect species associated with stored rice were identified during the storage period, namely lesser grain borer (Rhyzopertha dominica), red flour beetle (Tribolium castaneum), rice/maize weevil (Sitophilus spp.), angoumois grain moth (Sitotroga cerealella) and flat grain beetle (Cryptolestes ferrugineus). The lesser grain borer was the most predominant species with an average incidence above $70 \%$ after twelve months of storage, followed by the rice/maize weevil with an incidence of $17 \%$. When compared to hermetic storage containers, polypropylene bag showed the highest mean infestation level with 233.3 individuals/ $\mathrm{kg}$ after six months of storage, representing about 8-fold of the number of insects recorded in hermetic containers after six months of storage. In polypropylene container, the percentage of damaged grain and weight loss increased significantly achieving a maximum of $6.98 \%$ and $5.56 \%$ respectively, whereas using hermetic containers the highest percentage of damaged grain reached was $3.24 \%$ in polyethylene drum and the weight loss was $1.62 \%$ in GrainSafe bag. The results from the study show that the use of hermetic storage containers is a green alternative for safe storage of paddy rice, for 12 months without application of pesticides, bringing multiple advantages for smallholder farmers, lever food security and income generation for smallholder farmers and rice milling companies.
\end{abstract}

(ㅇ) 2020 Elsevier Ltd. All rights reserved.

\section{Introduction}

The agriculture sector in sub-Saharan Africa is dominated by small-scale farmers producing for their subsistence, with occasional surplus sold on local markets. Farmers in these countries regularly store their grains in traditional polypropylene bags placed in granaries made from local material such as bamboo, straw, mud, amongst others, due to its convenience and lower cost compared to improved storage structures. However, for long-term storage, these facilities are not effective against the major pests of cereal crops,

\footnotetext{
* Corresponding author.

E-mail address: rafaelnguenha@gmail.com (R. Nguenha).
}

mainly under high temperature and relative humidity regimes, typical of tropical regions, which may shorten the insect's life cycle, resulting in increased insect populations (Van Dyck et al., 2015; Phophi et al., 2020). To avoid losing their grain to pests on storage, farmers sell the grain just after harvest (Tefera et al., 2011a) when the market prices are low, but have to buy the grain at higher prices later when they are out of stock.

Rice is a staple food for more than half of the world's population and supplies over $20 \%$ of dietary calories consumed in the world (Prasad et al., 2014). In Mozambique, rice is considered a strategic crop where it is expected to contribute to the reduction of food insecurity, mainly in rural areas. The Government of Mozambique adopted the Green Revolution Strategy in 2007, and from this, the Strategic Plan for the Development of the Agricultural Sector 
(PEDSA) and the Action Plan for Food Productivity (PARPA) were developed to promote food security in the country. PARPA and PEDSA emphasize the need to reduce the gap existing between rice import and internal supply. According to a report from Bank of Mozambique, from 2015 to 2018, national rice production increased from 375305 to 412552 metric tonnes, representing a 10\% increase, whereas, for the same period, rice import almost doubled, from 749775 to 1142951 metric tonnes, representing an increase of the national deficit from 49.9\% to almost 63.9\% (Banco de Moçambique, 2019). Rice is mostly produced by smallholder farmers under rainfed conditions using traditional varieties with low use of inputs. Consequently, the average rice yield in Mozambique has been estimated to be around 1.0 ton/ha in the last three decades (Kajisa and Payongayong, 2011; Guenha et al., 2014), which is lower than the average in sub-Saharan Africa estimated at 2.1 ton/ha (Tsujimoto et al., 2019). In addition, a significant amount of rice grain is lost during storage, reducing the interest of this crop to smallholder farmers (Guenha et al., 2014).

In the southern region of Mozambique, most of the farmers usually do not store paddy rice for a long period, using it as a cash crop, and selling immediately after harvest, thus receiving a low price for their produce. On the other hand, the mill company is not able to keep the grain for an extended period as jute and polypropylene bags are used for storage. The company capacity to process the grain depends on the demand in local markets, and often the grain is kept with the husk for an entire agricultural season, which is prone to damage by insects.

During storage, paddy rice is attacked by many insect pests including angoumois grain moth [Sitotroga cerealella (Olivier) (Lepidoptera, Gelechiidae), lesser grain borer [Rhyzopertha dominica F. (Coleoptera, Bostrichidae)], rice/maize weevil [Sitophilus spp. (Coleoptera, Curculionidae) and red flour beetle [Tribolium castaneum (Herbst) (Coleoptera, Tenebrionidae)] (Guenha et al., 2014). In addition to direct quantity and quality losses, insect attack is also associated with mycotoxin contamination through the distribution of fungal inocula and creation of conditions that favour fungal growth and proliferation during storage (Milani, 2013). Synthetic pesticides are effective against insects and are important in reducing the level of losses during grain storage (Kumar and Kalita, 2017). Nevertheless, the use of these products poses some limitations due to their high cost, development of insect resistance, chemical residues in food and environmental contamination (Tapondjou et al., 2002; Silva et al., 2019). Furthermore, synthetic pesticides are effective for a certain period after application, making them not suitable for smallholder farmers in developing countries where open storage facilities are predominant and can allow insect pest re-infestation.

Cost-effective and non-chemical technologies have the potential to contribute to the reduction of grain losses during storage and increase the farmers' livelihood. The hermetic system is an alternative for using synthetic pesticides in grain protection during storage of small and large quantities, providing economic and environmental benefits (Villers et al., 2006; Villers et al., 2008). This technology creates an environment depleted in oxygen and rich in carbon dioxide due to the respiration of the biotic part of the grain (insects, aerobic microorganisms, and the grain itself) leading to insect inactivity and eventual death by suffocation (MorenoMartinez et al., 2000; Guenha et al., 2014; Njoroge et al., 2014; Kumar and Kalita, 2017) and desiccation due to inadequate water supply as a result of oxygen depletion (Murdock et al., 2012). Moreover, the oxygen depleted and carbon dioxide rich environment reduces the development of aerobic fungi, production of mycotoxin and reduces grain metabolic activity leading to its preservation (Lêda et al., 2009). Ng'ang'a et al. (2016) reported a decrease in aflatoxin production ability of Aspergillus flavus Link when maize was stored at a moisture content below $14 \%$ in hermetic conditions.

Various hermetic technologies, including metal silos, PICS bags, polyethylene drums, GrainPro GrainSafe bags and GrainPro Super Grain Bags, have been developed and promoted in many African countries. Previous studies have shown that high-density polyethylene drums and GrainSafe bags are effective in controlling insect multiplication and reducing grain damage in maize and wheat under smallholder farmers conditions in Africa (Abass et al., 2018; Walker et al., 2018; Kalsa et al., 2019). High-density polyethylene drums can also protect the grain against rodents during storage, have a lifespan of over 15 years, representing a good investment for farmers. The use of Super Grain Bag for rice storage in Mozambique was previously evaluated by Guenha et al. (2014) using simple and duplicated bags. It was reported that, when compared to polypropylene bags, Super Grain Bags can reduce losses by around 10fold over six months' storage period. However, the fact that some farmers, including processing companies, store their grain for at least nine months prompts the need to evaluate polypropylene bags and Super Grain Bag under climatic conditions in Mozambique for a longer period. Therefore, this study aims to evaluate the effectiveness of hermetic containers to preserve rice quality during storage. The technologies have the potential to reduce postharvest losses (PHL) at farmer's level and contribute to improved food and nutrition security in Mozambique, where rice is a staple.

\section{Material and methods}

\subsection{Site description and trial timing}

The experiment was conducted in Umbeluzi Agricultural Station, Institute for Agrarian Research of Mozambique (IIAM), Boane District. Boane District is located in the South of Maputo Province and borders in the North with Moamba District in the West and Southeast with Namaacha District in the South and Southeast with Matutuine District and the East with Matola Municipality (Fig. 1). It is a district with a dry tropical climate, with two well-defined seasons, the dry season (between April and September) and the rainy season (between October and March). The average annual temperature is $23.7{ }^{\circ} \mathrm{C}$ and the average annual precipitation is around $752 \mathrm{~mm}$ (Matule and Macarringue, 2020). June and July are the coldest months, whereas January and February are the hottest months in the district. The average annual relative humidity is $80.5 \%$, with a maximum of $86.0 \%$ in July and a minimum of $73.5 \%$ in November (Tandane, 2015). The experiment was conducted for one year, from February 2016 to February 2017.

\subsection{Paddy origin and variety}

The paddy used in the experiment was obtained from rice mill company Inacio de Sousa, Lda, in Manhiça district, Maputo province, Mozambique. The rice variety used was ITA 312 and was produced by smallholder farmers in 2015/2016 agricultural season. This variety is one of the most cultivated in Mozambique, mainly in the southern region.

\subsection{Treatments}

Five storage containers were evaluated: 1) Traditional polypropylene bags (control - PP), filled with $50 \mathrm{~kg}$ of paddy grain; 2) Super Grain Bags (SGB), filled with $50 \mathrm{~kg}$; 3) Polyethylene Drums (PD), filled with $210 \mathrm{~kg}$; 4) Polyethylene Silo Tanks (PST), filled with $750 \mathrm{~kg}$; and 5) GrainSafe bags (GB), filled with $1000 \mathrm{~kg}$.

Super Grain Bags and GrainSafe bags were manufactured by GrainPro, Inc., based in the United States of America. The 


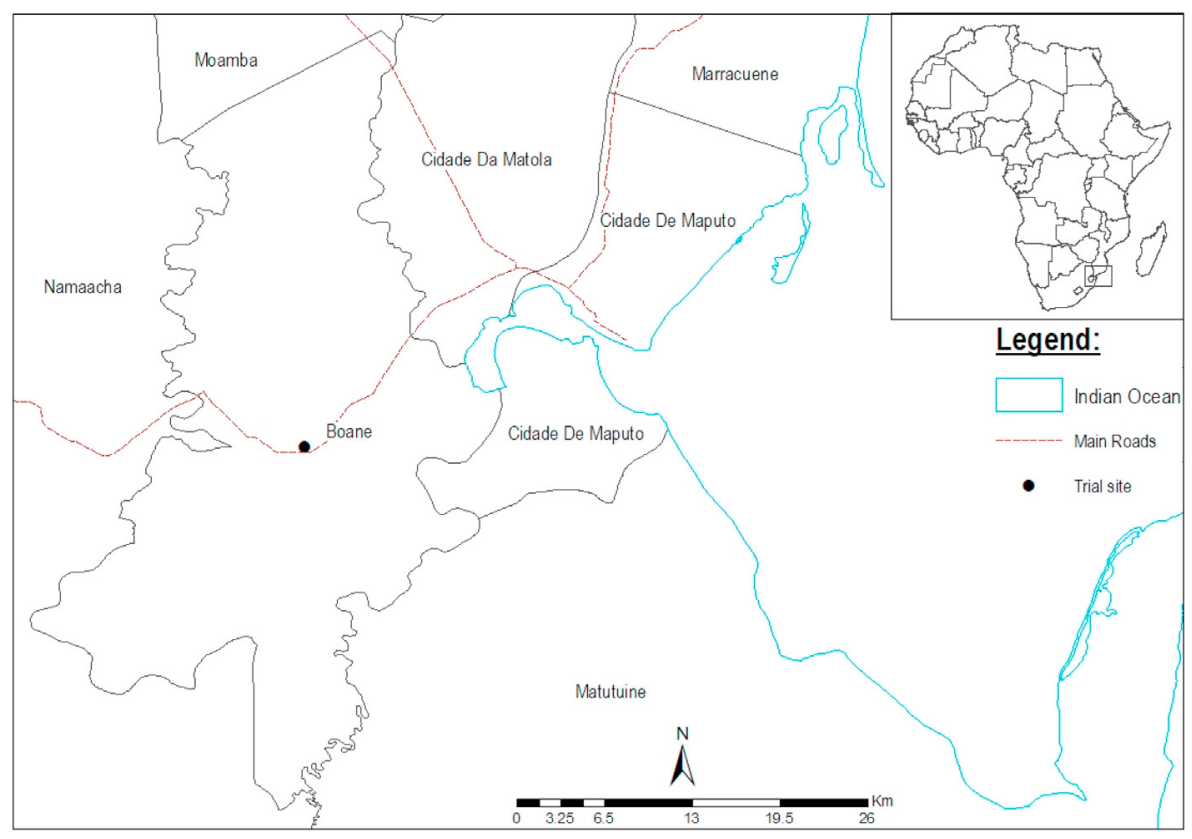

Fig. 1. Location of paddy rice storage experiment site.

polyethylene silo tank and polyethylene drum were manufactured locally by Plastex Lda (Mozambique) and are originally used for water storage. The polyethylene silo tank was adapted by increasing the outlet hole to facilitate rice paddy outflow. The material used for polyethylene containers has GRAS (Generally Recognized as Safe) status, according to the Ministry of Health of Mozambique.

Storgard WB probe traps (Trécé, Inc., Oklahoma, USA) were placed in the middle of all storage containers. A total of $6180 \mathrm{~kg}$ of paddy rice were used in the experiment, and all the containers were replicated three times. For protection against puncture and damage, Super Grain Bag was placed into the traditional polypropylene bag, as recommended by the manufacturer. The bags were randomly kept on pallets inside the warehouse at ambient conditions, in a randomised complete design. Glue traps were placed surrounding the experiment for rodent management.

\subsection{Grain sampling}

Grain sampling was conducted using the methodology described by Webley (1985). According to the author, when the number of bags containing cereals in a store is between 10 and 100 , about 10 bags should be sampled for analysis. Therefore, before filling the storage containers, ten bags of $75 \mathrm{~kg}$, containing the paddy rice, were randomly selected, from a universe of 88 bags to determine the initial degree of insect infestation, damaged grain, and grain moisture content. During the experiments, samples were taken every three months from the storage containers for laboratory analysis. Several samples were taken in three points, top, middle and bottom using double tube sampling spears. Same size sampling probes were used for all the storage containers. About $400 \mathrm{~g}$ of six subsamples were taken and mixed thoroughly totalizing $2.4 \mathrm{~kg}$, from which a final working sample of $1.0 \mathrm{~kg}$ was obtained using coning and quartering method, as described by Webley (1985). Briefly, after thoroughly mixing the grain a cone was formed in a flat surface. The cone was then flattened and divided into two equal halves which were also halved afterwards. Two diagonally opposite quarters of the grains were removed from the working area, and the remaining grain was mixed, and weighed. This process was repeated until $1 \mathrm{~kg}$ of the grain was obtained.

The following data was gathered during the experiment: infestation level, percentage of damaged grain, weight loss and grain moisture content. The Storgard WB probe traps were emptied in every sampling and replaced in the containers. Samples were transported from the experimental site to the laboratory in airtight plastic packaging to preserve their integrity.

\subsection{Insect population and damage assessment}

\subsubsection{Mean insect density}

Insects were collected in a composite sample of $1.0 \mathrm{~kg}$, identified and counted using standard approaches. Damaged paddy rice was opened to remove insects lodged inside. Insect density, referred to the number of insects per kilogram of paddy rice, was calculated by dividing the number of adult insects (live and dead altogether) by the grain sample weight.

Adult insects in Storgard WB probe were also counted by species and reported for each treatment.

\subsubsection{Grain damage and weight loss}

The weight loss was estimated using count and weight method proposed by Adams and Schulten (1978). For each test, three replicates of 1000 grains were taken randomly from the laboratory sample. The grain was sieved and winnowed to removed foreign material and dust. After cleaning, the samples were visually examined using a hand magnifier and separated into two categories: (i) damaged grain by insects (grains with hole or burrow) and (ii) undamaged grain, and each category was counted and weighed. The weight loss and the percentage of damaged grains were calculated using the following formula:

$\%$ weight loss $=\frac{(\mathrm{ab})-(\mathrm{cd})}{\mathrm{a}(\mathrm{d}+\mathrm{b})} 100$

$\%$ damaged grains $=\mathrm{d} / \mathrm{a}$ 
Where $a$ is the weight of undamaged grains, $b$ the number of undamaged grain, $c$ the weight of damaged grains, $d$ the number of damaged grains and $e$ the total number of grains.

\subsection{Paddy rice moisture content}

Paddy moisture content was determined according to the ISO712:2009 Cereals and cereal products - Determination of moisture content - Reference method (Guenha et al., 2014). Two subsamples of $5 \pm 0.001 \mathrm{~g}$ were used from each replicate. The samples were dried in an oven for $24 \mathrm{~h}$ at $105 \pm 3{ }^{\circ} \mathrm{C}$, and then reweighed. The moisture content was calculated using the following equation:

$m_{c}=\frac{(W w-W d)}{W d}$

where $m c$ is moisture content, $W_{w}$ is wet weight and $W_{d}$ is dry weight.

\subsection{Temperature and relative humidity monitoring}

During the experiment, the temperature and relative humidity were continuously monitored inside the storage containers, by placing data loggers in the middle of the containers, and in the warehouse environment, using data loggers HOBO UX100-011 and HOBO UX120-006 M (Onset Hobo® Data Loggers, MA, USA). The data logger sensors have an accuracy of $\pm 0.21{ }^{\circ} \mathrm{C}$ for temperature and $\pm 2.5 \%$ for relative humidity. The sensors were placed in different points of the storage containers, top, bottom and in the middle, and mean values were used for analysis. Three sensors were used in each structure, which were set to collect data at 1-h interval.

\subsection{Data analysis}

The data were expressed as mean \pm standard error (SE). Microsoft Excel and SPSS 20.0 software were used for data analysis. The significance of observed differences was evaluated by two-way factorial ANOVA analysis. When significant differences were observed, Tukey's HSD mean separation test under 95\% confidence limits was used to separate the treatment means. Correlation analyses were done using the Pearson Product-Moment Correlation Coefficient.

\section{Results}

\subsection{Insect species identified and mean density}

\subsubsection{Insects species}

The mean number of different species of insects captured per $\mathrm{kg}$ of paddy is presented in Table 1 . Five species were identified over the storage period, namely lesser grain borer ( $R$. dominica), red flour beetle ( $T$. castaneum), rice/maize weevil (Sitophilus spp.), angoumois grain moth (S. cerealella) and flat grain beetle [Cryptolestes ferrugineus (Stephens)].

\subsubsection{Mean insect density}

The lesser grain borer was the most predominant species throughout the storage period with an incidence of about $71 \%$ at twelfth month, followed by the rice/maize weevil with an incidence of $17 \%$ (Table 1 ). Sitotroga cerealella were the least predominant species in all hermetic containers, with densities below 2 individuals $/ \mathrm{kg}$ after six months of storage. From the sixth month to the end of the trial at twelfth month, S. cerealella were not detected in any hermetic container. In polypropylene bag, the highest density of $S$. cerealella was observed after six months of storage, with 23.3 individuals $/ \mathrm{kg}$, a 2 -fold increase compared to the initial density. The flat grain beetle was only present in polypropylene bags in the sixth month of storage and with an incidence of $2.1 \%$.

At the beginning of the experiment, the number of total insects in the paddy was 87.2 individuals $/ \mathrm{kg}$. There were significant differences $(P<0.001)$ between polypropylene bags and hermetic containers in the number of insects over the storage period. After three months of storage, the number of insects in polypropylene bags increased by $48 \%$, which was a significant increase when compared to the initial infestation level $\left(F_{4,69}=11.38 ; P<0.0001\right)$ and was different from all the hermetic storage containers. For grain stored hermetically, the number of insects reduced significantly in the first three months of storage, and there were also significant differences among the hermetic containers $\left(F_{4,69}=10.7\right.$; $P<0.05)$. The lowest number of insects after three months of storage was observed in the grain held in polyethylene drum, reducing the initial infestation by $77.3 \%$. The GrainSafe bag showed the least reduction of the insect population among the hermetic containers, with $48 \%$ reduction of the initial population of insects.

After six months of storage, the number of insects in polypropylene bag increased by $80 \%$ compared to previous sampling period $\left(F_{4,69}=27.79 ; P<0.001\right)$. On the contrary, except for SafeGrain bag, the average number of insects in hermetic containers remained stable in the same period, and no significant differences were observed among them $\left(F_{4,69}=14.32 ; P=0.26\right)$. In the SafeGrain bag, the number of insects reduced by about 2 -fold after six months of storage, compared to the previous sampling period. After twelve months of storage, the initial infestation level in hermetic containers was reduced by $57 \%-72 \%$, with an average of $66 \%$ reduction level. Overall, all the hermetic containers were effective in reducing the proliferation of insects along the storage period.

After three months of storage, the number of insects in probes did not differ significantly in all the storage containers $\left(F_{3,59}=2.87\right.$; $P=0.08$ ) (Table 2). However, a significant increase in the number of living insects was observed in polypropylene bag, achieving 122.00 insects/probe after six months of storage $\left(F_{3,59}=37.46 ; P<0.0001\right)$, and from there onward it remained stable and different from all the hermetic containers. Polyethylene drum, polyethylene silo tank, and Super Grain Bag were not significantly different from each other from the sixth months of storage and kept the number of living insects inside the probes stable over the storage period. On the other hand, although not significant, an increase in the number of living insects occurred in the grain stored in GrainSafe bag, achieving 43 insects $/ \mathrm{kg}$ at the end of the storage period. However, it is important to note that the number of insects in GrainSafe bag was still 3-fold lower than that observed in polypropylene bag. The relative abundance of different species inside the probes was similar to that observed inside the storage containers. Therefore, only the total number of insects is reported for probes.

\subsection{Grain damage and weight loss}

At the beginning of the experiment, $1.73 \%$ of the grain was damaged. There were significant differences in the percentage of damaged grain between polypropylene bags and hermetic containers over the storage period $\left(F_{4,69}=18.61 ; P<0.001\right)$ (Fig. 2$)$. The percentage of damaged grain increased significantly in the first six months of storage in polypropylene bag, an increase by over $300 \%$, which represents the maximum increase for this structure $\left(F_{4,69}=91.67 ; P<0.001\right)$. Surprisingly, a declining trend was observed in damaged grain in polypropylene bags after the sixth month of to the termination of the trial. The polyethylene drum also recorded a significant increase of damaged grain in the first six 
Table 1

Mean total number of insect species identified in different storage containers and the respective percentage abundance over 12 months of storage (mean $\pm S E$ ).

\begin{tabular}{|c|c|c|c|c|c|c|c|}
\hline \multirow[t]{2}{*}{ Storage period (months) } & \multirow[t]{2}{*}{ Storage structure } & \multicolumn{5}{|c|}{ Insect species (number of insects/kg) } & \multirow[b]{2}{*}{ Total } \\
\hline & & R. dominica & Sitophilus spp. & T. castaneum & S. cerealella & C. ferrugineus & \\
\hline 0 & $\%$ & $\begin{array}{l}62.6 \pm 1.1 \\
71.8\end{array}$ & $\begin{array}{l}7.6 \pm 1.1 \\
8.7\end{array}$ & $\begin{array}{l}4.8 \pm 0.5 \\
5.5\end{array}$ & $\begin{array}{l}12.2 \pm 1.1 \\
14.0\end{array}$ & $\begin{array}{l}0.0 \pm 0.0 \\
0.0\end{array}$ & $\begin{array}{l}87.2 \pm 5.5 \\
-\end{array}$ \\
\hline \multirow[t]{2}{*}{3} & $\begin{array}{l}\text { PP } \\
\text { SGB } \\
\text { PD } \\
\text { PST } \\
\text { GB }\end{array}$ & $\begin{array}{l}92.3 \pm 8.3 \mathrm{~A} \\
18.7 \pm 2.1 \mathrm{CD} \\
11.7 \pm 3.4 \mathrm{D} \\
22.3 \pm 5.0 \mathrm{C} \\
31.3 \pm 8.0 \mathrm{~B} \\
\end{array}$ & $\begin{array}{l}28.7 \pm 6.9 \mathrm{~A} \\
9.3 \pm 2.0 \mathrm{~B} \\
1.7 \pm 0.3 \mathrm{C} \\
9.7 \pm 2.9 \mathrm{~B} \\
9.0 \pm 2.9 \mathrm{~B} \\
\end{array}$ & $\begin{array}{l}6.3 \pm 2.2 \mathrm{~A} \\
7.3 \pm 1.5 \mathrm{~A} \\
4.7 \pm 0.3 \mathrm{~A} \\
0.3 \pm 0.3 \mathrm{~B} \\
5.0 \pm 0.5 \mathrm{~A} \\
\end{array}$ & $\begin{array}{l}2.0 \pm 0.0 \mathrm{~A} \\
0.0 \pm 0.0 \mathrm{~B} \\
1.7 \pm 0.7 \mathrm{~A} \\
0.3 \pm 0.3 \mathrm{~A} \\
0.0 \pm 0.0 \mathrm{~B}\end{array}$ & $\begin{array}{l}0.0 \pm 0.0 \\
0.0 \pm 0.0 \\
0.0 \pm 0.0 \\
0.0 \pm 0.0 \\
0.0 \pm 0.0\end{array}$ & $\begin{array}{l}129.3 \pm 11.9 \mathrm{Ab} \\
35.3 \pm 2.9 \mathrm{Ba} \\
19.8 \pm 2.2 \mathrm{Cb} \\
32.6 \pm 4.5 \mathrm{Ba} \\
45.3 \pm 6.7 \mathrm{Ba}\end{array}$ \\
\hline & $\begin{array}{l}\text { Total } \\
\%\end{array}$ & $\begin{array}{l}221.6 \pm 13.1 \\
74.2\end{array}$ & $\begin{array}{l}49.4 \pm 4.0 \\
16.6\end{array}$ & $\begin{array}{l}23.6 \pm 1.1 \\
7.9\end{array}$ & $\begin{array}{l}4.0 \pm 0.4 \\
1.3\end{array}$ & $\begin{array}{l}0.0 \pm 0.0 \\
0.0\end{array}$ & $\begin{array}{l}298.6 \pm 19.0 \\
-\end{array}$ \\
\hline \multirow[t]{2}{*}{6} & $\begin{array}{l}\text { PP } \\
\text { SGB } \\
\text { PD } \\
\text { PST } \\
\text { GB } \\
\end{array}$ & $\begin{array}{l}167.0 \pm 10.3 \mathrm{~A} \\
12.7 \pm 1.9 \mathrm{~B} \\
13.0 \pm 2.9 \mathrm{~B} \\
14.0 \pm 4.6 \mathrm{~B} \\
15.3 \pm 3.8 \mathrm{~B} \\
\end{array}$ & $\begin{array}{l}19.7 \pm 1.1 \mathrm{~A} \\
4.0 \pm 0.9 \mathrm{~B} \\
3.3 \pm 0.3 \mathrm{~B} \\
2.0 \pm 0.9 \mathrm{~B} \\
3.0 \pm 0.9 \mathrm{~B} \\
\end{array}$ & $\begin{array}{l}16.3 \pm 1.4 \mathrm{~A} \\
8.3 \pm 0.5 \mathrm{~B} \\
4.7 \pm 2.7 \mathrm{~B} \\
7.3 \pm 4.8 \mathrm{~B} \\
6.3 \pm 2.0 \mathrm{~B} \\
\end{array}$ & $\begin{array}{l}23.3 \pm 5.8 \mathrm{~A} \\
2.0 \pm 1.0 \mathrm{~B} \\
1.7 \pm 0.7 \mathrm{~B} \\
1.3 \pm 0.7 \mathrm{~B} \\
1.0 \pm 0.5 \mathrm{~B} \\
\end{array}$ & $\begin{array}{l}7.0 \pm 1.7 \mathrm{~A} \\
0.0 \pm 0.0 \mathrm{~B} \\
0.0 \pm 0.0 \mathrm{~B} \\
0.0 \pm 0.0 \mathrm{~B} \\
0.0 \pm 0.0 \mathrm{~B}\end{array}$ & $\begin{array}{l}233.3 \pm 27.0 \mathrm{Aa} \\
28.0 \pm 2.0 \mathrm{Ba} \\
22.7 \pm 2.2 \mathrm{Bab} \\
24.6 \pm 2.5 \mathrm{Bab} \\
25.6 \pm 2.7 \mathrm{Bb}\end{array}$ \\
\hline & $\begin{array}{l}\text { Total } \\
\%\end{array}$ & $\begin{array}{l}222.0 \pm 27.4 \\
66.6\end{array}$ & $\begin{array}{l}32.0 \pm 3.0 \\
9.6\end{array}$ & $\begin{array}{l}42.9 \pm 1.8 \\
12.9\end{array}$ & $\begin{array}{l}29.3 \pm 3.9 \\
8.8\end{array}$ & $\begin{array}{l}7.0 \pm 1.5 \\
2.1\end{array}$ & $\begin{array}{l}333.2 \pm 37.2 \\
-\end{array}$ \\
\hline \multirow[t]{2}{*}{9} & $\begin{array}{l}\text { PP } \\
\text { SGB } \\
\text { PD } \\
\text { PST } \\
\text { GB }\end{array}$ & $\begin{array}{l}155.0 \pm 34.2 \mathrm{~A} \\
18.3 \pm 0.3 \mathrm{~B} \\
15.3 \pm 1.0 \mathrm{~B} \\
11.3 \pm 1.9 \mathrm{~B} \\
13.3 \pm 1.2 \mathrm{~B} \\
\end{array}$ & $\begin{array}{l}29.7 \pm 3.1 \mathrm{~A} \\
3.7 \pm 0.5 \mathrm{~B} \\
2.0 \pm 0.8 \mathrm{~B} \\
0.3 \pm 0.3 \mathrm{C} \\
0.3 \pm 0.0 \mathrm{C} \\
\end{array}$ & $\begin{array}{l}10.7 \pm 1.8 \mathrm{~A} \\
5.3 \pm 1.0 \mathrm{~B} \\
7.3 \pm 1.7 \mathrm{~B} \\
7.3 \pm 1.7 \mathrm{~B} \\
11.0 \pm 1.4 \mathrm{~B} \\
\end{array}$ & $\begin{array}{l}20.0 \pm 0.5 \mathrm{~A} \\
0.0 \pm 0.0 \mathrm{~B} \\
0.0 \pm 0.0 \mathrm{~B} \\
0.0 \pm 0.0 \mathrm{~B} \\
0.0 \pm 0.0 \mathrm{~B} \\
\end{array}$ & $\begin{array}{l}0.0 \pm 0.0 \\
0.0 \pm 0.0 \\
0.0 \pm 0.0 \\
0.0 \pm 0.0 \\
0.0 \pm 0.0\end{array}$ & $\begin{array}{l}217.2 \pm 30.9 \mathrm{Aa} \\
27.3 \pm 3.8 \mathrm{Ba} \\
24.6 \pm 3.2 \mathrm{Bab} \\
18.9 \pm 2.6 \mathrm{Bb} \\
24.6 \pm 3.3 \mathrm{Bb} \\
\end{array}$ \\
\hline & $\begin{array}{l}\text { Total } \\
\%\end{array}$ & $\begin{array}{l}213.2 \pm 25.1 \\
68.6\end{array}$ & $\begin{array}{l}36.0 \pm 5.1 \\
11.6\end{array}$ & $\begin{array}{l}41.6 \pm 1.0 \\
13.4\end{array}$ & $\begin{array}{l}20.0 \pm 3.6 \\
6.4\end{array}$ & $\begin{array}{l}0.0 \pm 0.0 \\
0.0\end{array}$ & $\begin{array}{l}310.8 \pm 34.6 \\
-\end{array}$ \\
\hline \multirow[t]{2}{*}{12} & $\begin{array}{l}\text { PP } \\
\text { SGB } \\
\text { PD } \\
\text { PST } \\
\text { GB }\end{array}$ & $\begin{array}{l}193.3 \pm 62.0 \mathrm{~A} \\
21.7 \pm 2.3 \mathrm{~B} \\
20.3 \pm 2.4 \mathrm{~B} \\
19.3 \pm 2.2 \mathrm{BCE} \\
12.3 \pm 2.4 \mathrm{C}\end{array}$ & $\begin{array}{l}37.4 \pm 5.3 \mathrm{~A} \\
11.3 \pm 7.6 \mathrm{~B} \\
2.0 \pm 1.6 \mathrm{C} \\
1.7 \pm 1.4 \mathrm{C} \\
10.3 \pm 3.4 \mathrm{~A}\end{array}$ & $\begin{array}{l}28.0 \pm 13.2 \mathrm{~A} \\
4.7 \pm 1.1 \mathrm{~B} \\
7.3 \pm 4.5 \mathrm{~B} \\
5.3 \pm 1.0 \mathrm{~B} \\
2.0 \pm 1.6 \mathrm{~B} \\
\end{array}$ & $\begin{array}{l}0.0 \pm 0.0 \\
0.0 \pm 0.0 \\
0.0 \pm 0.0 \\
0.0 \pm 0.0 \\
0.0 \pm 0.0\end{array}$ & $\begin{array}{l}0.0 \pm 0.0 \\
0.0 \pm 0.0 \\
0.0 \pm 0.0 \\
0.0 \pm 0.0 \\
0.0 \pm 0.0\end{array}$ & $\begin{array}{l}258.7 \pm 35.7 \mathrm{Aa} \\
37.7 \pm 4.0 \mathrm{Ba} \\
29.6 \pm 4.4 \mathrm{Ba} \\
26.3 \pm 4.4 \mathrm{Bab} \\
24.6 \pm 2.6 \mathrm{Bb}\end{array}$ \\
\hline & $\begin{array}{l}\text { Total } \\
\%\end{array}$ & $\begin{array}{l}266.9 \pm 41.0 \\
70.8\end{array}$ & $\begin{array}{l}62.7 \pm 31.3 \\
16.6\end{array}$ & $\begin{array}{l}47.3 \pm 5.8 \\
12.6\end{array}$ & $\begin{array}{l}0.0 \pm 0.0 \\
0.0\end{array}$ & $\begin{array}{l}0.0 \pm 0.0 \\
0.0\end{array}$ & $\begin{array}{l}376.9 \pm \\
-\end{array}$ \\
\hline
\end{tabular}

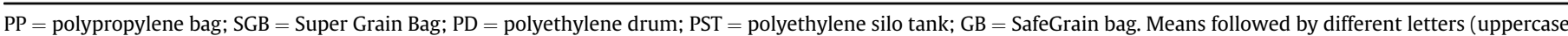
letter for storage containers in the same period and lowercase letter for different periods in the same storage structure) are significantly different $(p<0.05)$.

Table 2

Mean number $( \pm S E)$ of live insects in each storage container (insects/probe) over 12 months of storage (mean.

\begin{tabular}{|c|c|c|c|c|}
\hline \multirow[t]{2}{*}{ Storage structure } & \multicolumn{4}{|c|}{ Storage period (months) } \\
\hline & 3 & 6 & 9 & 12 \\
\hline PP & $45.3 \pm 4.3 \mathrm{Aa}$ & $122.0 \pm 3.8 \mathrm{Ab}$ & $114.3 \pm 6.4 \mathrm{Ab}$ & $112.3 \pm 7.9 \mathrm{Ab}$ \\
\hline SGB & $14.7 \pm 4.4 \mathrm{Aa}$ & $10.3 \pm 2.2 \mathrm{Ba}$ & $13.7 \pm 3.8 \mathrm{Ba}$ & $11.67 \pm 3.8 \mathrm{Ba}$ \\
\hline PD & $6.7 \pm 2.8 \mathrm{Aa}$ & $6.7 \pm 2.7 \mathrm{Ba}$ & $5.3 \pm 0.3 \mathrm{Ba}$ & $7.33 \pm 2.7 \mathrm{Ba}$ \\
\hline PST & $37.3 \pm 17.6 \mathrm{Aa}$ & $4.00 \pm 2.1 \mathrm{Bb}$ & $4.33 \pm 2.0 \mathrm{Bb}$ & $3.67 \pm 2.2 \mathrm{Bb}$ \\
\hline GB & $26.3 \pm 9.0 \mathrm{Aa}$ & $38.67 \pm 19.4 \mathrm{Ca}$ & $41.00 \pm 18.5 \mathrm{Ca}$ & $43.00 \pm 21.1 \mathrm{C}$ \\
\hline
\end{tabular}

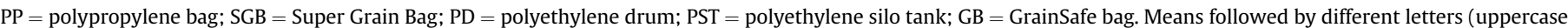
letter in column and lowercase letter in line) are significantly different $(p<0.05)$.

months of storage, with $89 \%$ increase from the initial damage level $\left(F_{4,69}=17.94 ; P<0.05\right)$. However, the percentage of damaged grain in the latter structure was less than half of that recorded in polypropylene bag. All the other containers (Super Grain Bag, polyethylene silo tank and GrainSafe bag) were effective in preventing the damage of paddy rice grain by insects over 12 months of storage, where the increase ranged from $47 \%$ to $6 \%$, with an average of 32.5\%. Therefore, despite a high initial insect infestation level, hermetic storage containers were able to maintain the grain damage level stable along the storage period by controlling insects' multiplication.

The highest percentage of loss was observed in polypropylene bag after six months of storage, with an increase by 3-fold of the weight loss registered in the same structure after three months of storage (Fig. 3). However, the weight loss in polypropylene bag decreased by around $50 \%$ from sixth to ninth month of storage. All the hermetic containers maintained the grain weight stable in the first six months of storage and did not differ significantly among each other. However, from six to nine months of storage, the weight loss increased significantly by $38 \%$ and $30 \%$ in Super Grain Bag and polyethylene silo tank respectively but remained stable in the last three months of storage. For all storage containers, we did not observe a significant increase in weight loss in the last three months of storage. There was a significant positive relationship between the insect infestation level and the percentage of damaged grain $(r=0.83, P<0.001)$, and between the insect infestation level and the percentage of weight losses $(r=0.85, P<0.001)$.

Means followed by different letters (uppercase letter for periods considering the same storage structure and lowercase letter for storage containers in the same period) are significantly different 


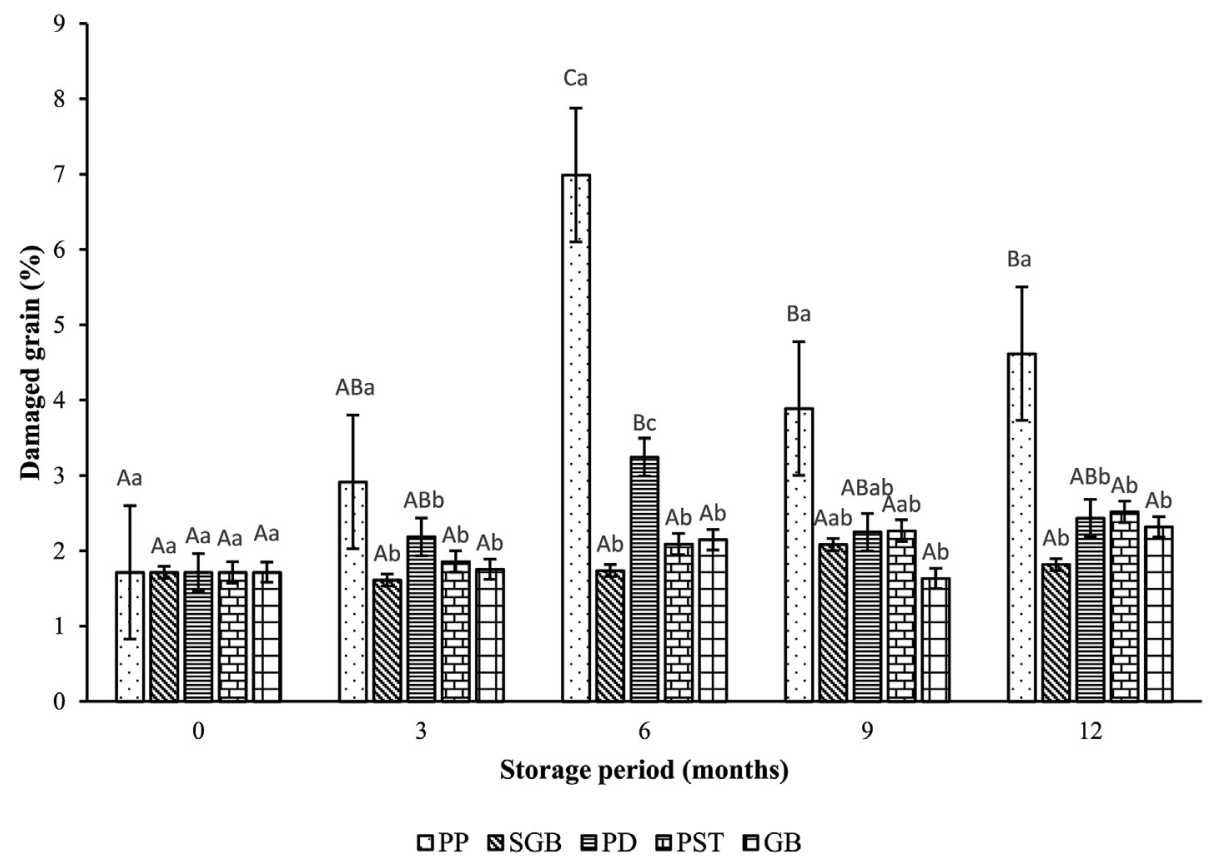

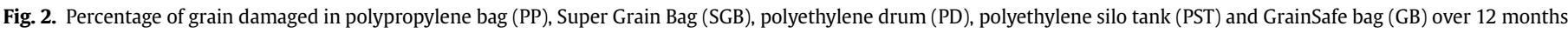

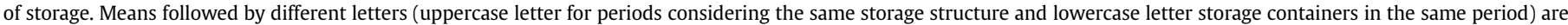
significantly different $(P<0.05)$.

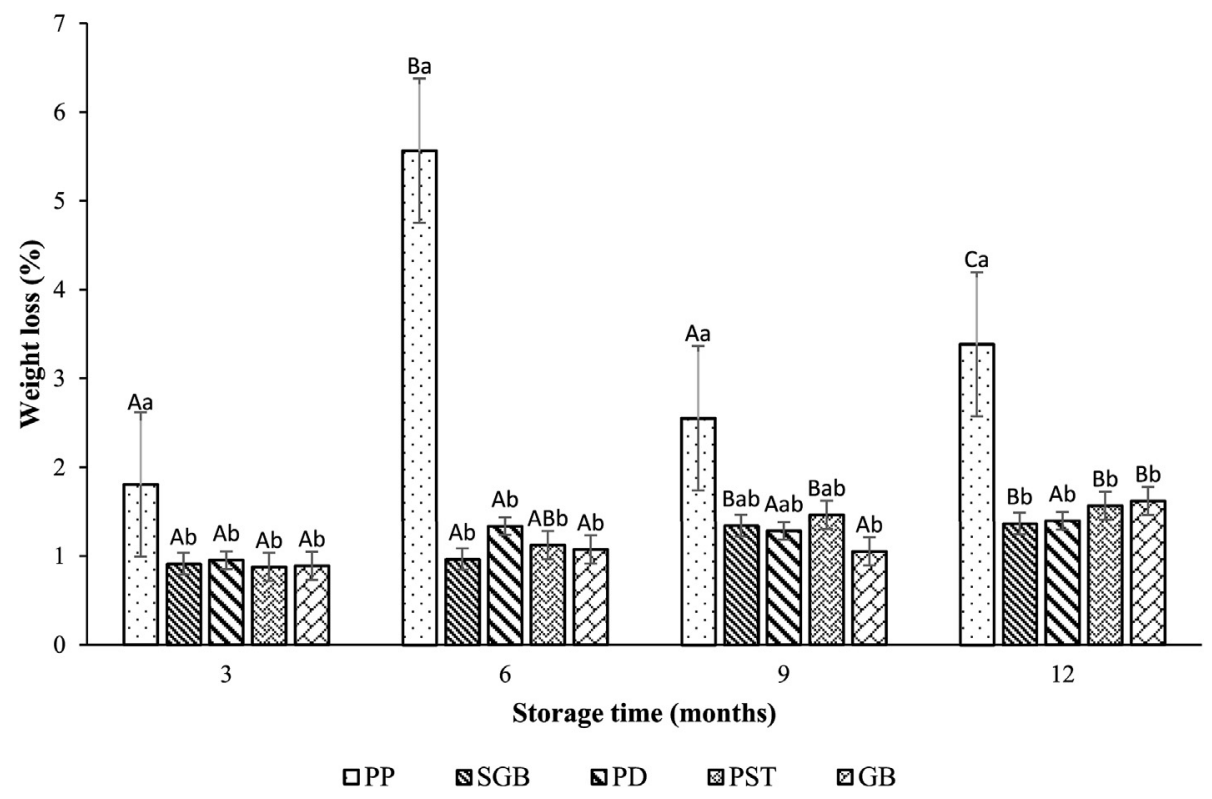

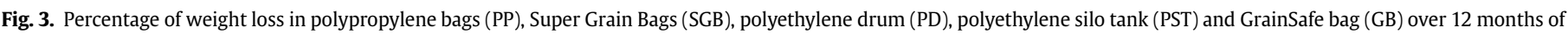
storage.

$(p<0.05)$.

\subsection{Grain moisture content}

The mean moisture content of paddy rice at the beginning of the experiment was 11.1\%. Variations in moisture content were assessed at 3-months interval basis. There was a significant $\left(F_{4,69}=10.92 ; P<0.0001\right)$ increase in the moisture content of grain stored in polypropylene bag (PB), Super Grain Bag (SGB) and polyethylene silo (PST) after six months of storage (Table 3), by $9.1 \%$,
$8,1 \%$ and $10.8 \%$ respectively. Under the same storage period, the grain stored in GrainSafe bags recorded the lowest moisture content, with a decrease by $9 \%$ compared to the initial moisture content. No significant change was observed in the moisture content of the grain stored in polyethylene drum (PD) over the storage period $\left(F_{4,69}=3.08 ; P=0.06\right)$. Regarding the treatments at the same period of storage, we observed significant differences $\left(F_{5,69}=3.15\right.$; $P<0.05)$ among the storage containers only in the ninth month of storage. At this period, GrainSafe bag showed the lowest moisture content, with $10.1 \%$, while all the other containers showed marginal 
Table 3

Mean value $( \pm S E)$ of moisture content of paddy rice stored in different storage containers over 12 months $(\mathrm{n}=3)$.

\begin{tabular}{|c|c|c|c|c|c|}
\hline \multirow[t]{2}{*}{ Storage containers } & \multicolumn{5}{|c|}{ Storage period (months) } \\
\hline & 0 & 3 & 6 & 9 & 12 \\
\hline $\mathrm{PP}$ & $11.1 \pm 0.1 \mathrm{Aa}$ & $11.9 \pm 0.2 \mathrm{Abc}$ & $12.1 \pm 0.0 \mathrm{ABb}$ & $10.8 \pm 0.2 \mathrm{Aa}$ & $11.4 \pm 0.2 \mathrm{Aac}$ \\
\hline SGB & $11.1 \pm 0.1 \mathrm{Aa}$ & $11.0 \pm 0.3 \mathrm{Aa}$ & $12.0 \pm 0.1 \mathrm{ABb}$ & $10.8 \pm 0.2 \mathrm{Aa}$ & $11.3 \pm 0.2 \mathrm{Aa}$ \\
\hline PD & $11.1 \pm 0.1 \mathrm{Aa}$ & $10.6 \pm 0.6 \mathrm{Aa}$ & $11.7 \pm 0.2 \mathrm{Aa}$ & $10.6 \pm 0.2 \mathrm{Aa}$ & $11.1 \pm 0.2 \mathrm{Aa}$ \\
\hline PST & $11.1 \pm 0.1 \mathrm{Aa}$ & $11.1 \pm 0.3 \mathrm{Aa}$ & $12.3 \pm 0.1 \mathrm{Bb}$ & $10.9 \pm 0.2 \mathrm{Aa}$ & $11.2 \pm 0.2 \mathrm{Aa}$ \\
\hline GB & $11.1 \pm 0.1 \mathrm{Aa}$ & $11.5 \pm 0.0 \mathrm{Ab}$ & $10.1 \pm 0.0 \mathrm{Cc}$ & $10.5 \pm 0.2 \mathrm{Ad}$ & $1.3 \pm 0.1 \mathrm{Aa}$ \\
\hline
\end{tabular}

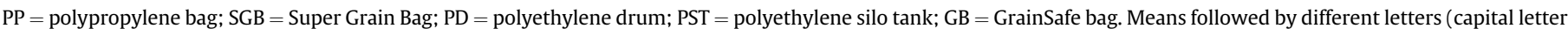
in column and lowercase letter in line) are significantly different $(p<0.05)$.

differences among each other. There was no significant correlation ( $r=0.15, P=0.535)$ between the grain moisture content and the relative humidity in the inter-granular spaces of all the storage containers under evaluation. It is worth noting that, after 12 months of storage, the moisture content in all the storage containers remained below $13 \%$.

\subsection{Temperature and relative humidity}

The variation of temperature was similar in all the containers under evaluation (Figs. 4 and 5). The data represent the mean values from the middle, bottom and top of the storage containers. The fifth month (Jun-16) corresponded to the coolest period of the year (peak of the winter in the region), while Feb-16 and Feb-17 (the beginning and the end of the experiment) were the hottest months (peak of the summer). Regarding relative humidity, it was observed that in polypropylene bag, the relative humidity in intergranular spaces showed fluctuations along the storage period, with the lowest values of relative humidity in the winter (from the fourth to the seventh month of storage). On the other hand, the relative humidity slightly changed in all the hermetic storages, with the lowest inter-granular relative humidity recorded in polyethylene drum.

\section{Discussion}

The baseline grain samples before the experiment showed the presence of insects, with 87.2 individuals $/ \mathrm{kg}$ of paddy rice. Insects can infest the grain when the crop is still on the field and continues their growth and multiplication during storage. Besides, before the grain was used in the experiment, it was stored for five months in a rice mill warehouse containing grain from previous agricultural seasons, which may have resulted in cross-contamination of the newly harvested grain. Therefore, although the experiment was conducted for 12 months, the grain has been effectively stored for 17 months, which may potentially have any effect on the performance of the tested storage containers. Grain stored shortly after harvest and drying would have a lower infestation level. Thus, the density of insects and the percentage of damaged grain and weight loss would be lower than the reported in the present study. A baseline study was conducted to assess the initial quality of the grain before it was placed in different storage containers, and all the conclusions made are based on the initial quality of the grain used.

The insects identified in this study, $R$. dominica, S. cerealella, Sitophilus spp., T. castaneum, and C. ferrugineus, are key pest insects in stored rice in tropical countries (Trematerra et al., 2004; Togola et al., 2013) and were previously associated with rice storage under polypropylene bags and Super Grain Bags at the same local where this experiment was conducted (Guenha et al., 2014). During the storage period, the population of $R$. dominica increased by $3-$ fold compared to the initial density, while the population of Tribolium spp. increased by 9-fold, representing the lowest and highest increasing rate for all insects identified, respectively. Rhyzopertha dominica is an internal primary pest, with the ability to attack intact grain resulting in scratched surfaces which can evolve into deep holes (Pires and Nogueira, 2018), causing secondary infestation by other pests. Due to its habit to develop inside the grain, $R$. dominica reduces the head rice yield leading to substantial

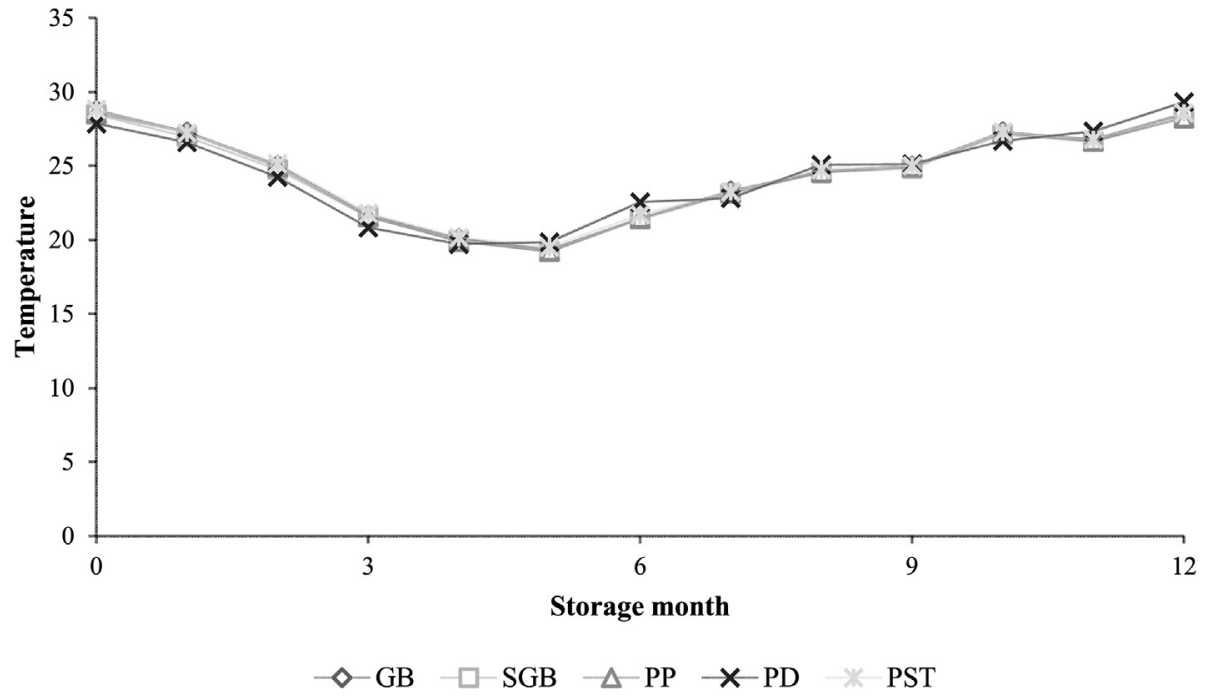

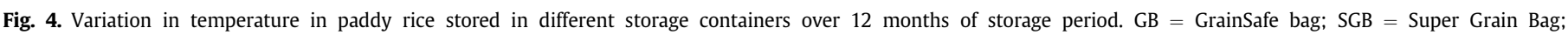
$\mathrm{PP}=$ polypropylene bag; $\mathrm{PD}=$ polyethylene drum; PST = polyethylene silo tank. 


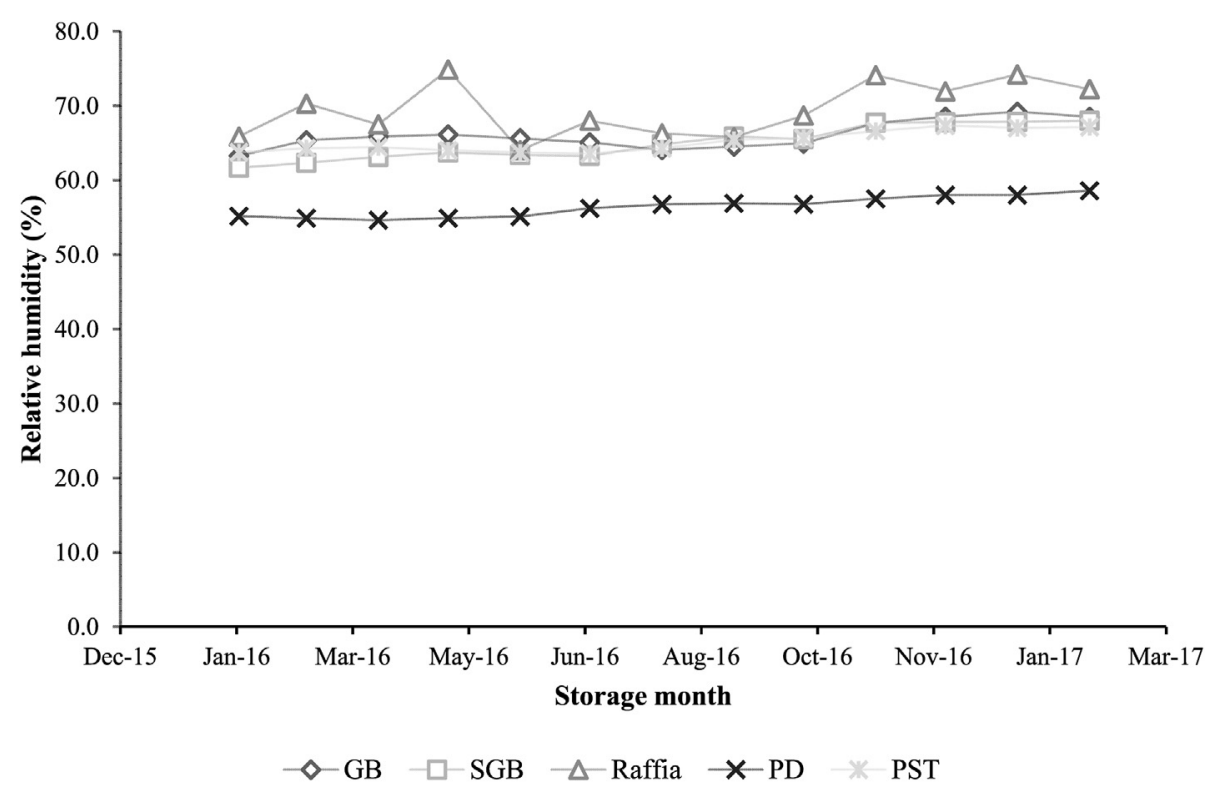

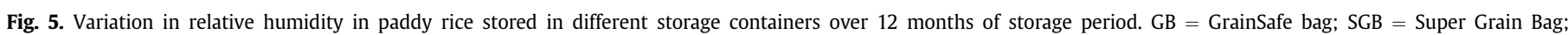
$\mathrm{PP}=$ polypropylene bag; $\mathrm{PD}=$ polyethylene drum; $\mathrm{PST}=$ polyethylene silo tank .

economic losses. On the other hand, Tribolium spp. are secondary pests as generally, they do not feed on undamaged grain (Li and Arbogast, 1991; Nansen et al., 2009; Nadeem et al., 2011). Thus, the population Tribolium spp. tend to increase with an increase in the level of grain deterioration (Waongo et al., 2019).

The population of $S$. cerealella almost doubled after six months of storage in polypropylene bags, achieving the highest density of 23.3 individuals $/ \mathrm{kg}$, while it was the less predominant species in hermetic containers with a density below 2 individuals/kg. Sitotroga cerealella have been reported to be highly sensitive to $\mathrm{CO}_{2}$ rich environments (Hashem and Reichmuth, 1994; Hashem et al., 2014) such as those created within hermetic containers.

The number of insects in polypropylene bags increased significantly after six months of storage, but a stable trend was observed henceforth until the termination of the trial. On the other hand, the hermetic storage containers were effective in reducing the proliferation of insects along the 12 months of storage, resulting in lower grain damage and weight loss. There were no significant differences amongst hermetic containers in their efficacy to suppress insect multiplication and mitigate grain damage and weight loss. Containers of different sizes were used in the present study. The Super Grain Bag and polypropylene bags were the smallest both with $50 \mathrm{~kg}$ of paddy, whereas the SafeGrain bag was the largest with $1000 \mathrm{~kg}$. Different container sizes may result in different microenvironmental conditions and insect dynamic amongst the containers. However, the polyethylene drum, polyethylene silo tank and SafeGrain bags were designed for high quantity and should be tested considering their practical use. Using lower quantity in the bigger containers could take longer to reach a significant decrease in the concentration of oxygen and carbon dioxide accumulation as a high oxygen volume would be available inside the containers. Therefore, the containers were used to their full capacity.

The reduction in the number of insects in hermetic containers after three months of storage is most likely a result of oxygen consumption and carbon dioxide accumulation due to respiratory metabolism of moulds, insects and the grain itself (Murdock et al., 2012). The effectiveness of hermetic containers in preventing insect proliferation during storage has been reported in several studies (Guenha et al., 2014; Chigoverah and Mvumi, 2016; Walker et al.,
2018; Kalsa et al., 2019). According to Villers et al. (2008) and Navarro (2012), in hermetic storage, the grain can be stored for up to 12 months without significant deterioration in the quality parameters, while by using polypropylene bags without pesticides, the grain can be safely stored for only three months. However, if the grain is stored with a high infestation, some insects such as $R$. dominica are capable of perforating the hermetic bags leading to the breakdown of hermeticity, and consequently, the containers become ineffective (García-Lara et al., 2013; Groote et al., 2013). It is common among smallholder farmers to put the freshly harvested grain in the same warehouse with grain from previous harvest, without cleaning the place. These places are often infested by insects, which could make holes in the containers such as Super Grain Bags and GrainSafe bags to access the inner grain making the containers hermetically ineffective (Likhayo et al., 2016). However, we did not observe any perforations due to insects or rodents in any of the storage containers under evaluation. The store was thoroughly cleaned before the experiment to prevent crosscontamination, and glue traps were used to manage rodents, and this measure may have contributed to prevent bags perforation during the trial.

Overall, a higher percentage of grain damage and weight loss was observed in polypropylene bags when compared to the hermetic storage system, and the highest values were recorded after six months of storage. Contrastingly, only a marginal increase in weight loss and grain damage were observed in grain held in hermetic conditions. The percentage of grain damaged by insects in polypropylene bags and polyethylene drum decreased from sixth to the ninth month of storage. In polypropylene bags, the same trend was observed for the percentage of weight loss. A decrease in grain damage and weight loss during storage has been reported in previous studies (Tefera et al., 2011b; De Groote et al., 2013; Abass et al., 2018; Tefera et al., 2018). It has been suggested that, at high infestation levels, grain kernels are destroyed by insects. Destroyed grains are not considered when counting the number of damaged grains (distinguished by the presence of holes), resulting in an underestimation of the percentage of grain damage and consequently the weight loss level (Tefera et al., 2011b).

The present findings are consistent with numerous previous 
studies reporting that hermetic containers can maintain grain quality of several commodities for over six months (Sanon et al., 2011; Hell et al., 2014; Baoua et al., 2016; Abass et al., 2018). Weight losses during storage are mainly caused by insect feeding on the grain and causing damage, but can also result on the fungal attack and grain metabolic activities such as respiration, although losses due to respiration are negligible in grain (Adhikarinayake et al., 2006; Baoua et al., 2014). The regression analysis showed that $72 \%$ of weight loss variation is explained by the insect density. Insects can also depreciate the grain quality and reduce the grain germination potential and vigour (Guenha et al., 2014). The hermetic storage system reduces these losses by controlling insects' growth and multiplication without the use of pesticides, making this approach environmentally friendly and cost-effective.

Results from this study show that the hermetic containers under analysis could be an alternative to protect rice grain in storage, without the need to apply pesticides. These results suggest that the use of hermetic containers can help to reduce food insecurity in rural areas, where the majority of Mozambican leave. Polyethylene silo tank and polyethylene drum have an additional advantage of being resistance to rodent attacks and cannot be perforated by insects both from in and outside the structure. Additionally, according to the manufacturer company, the life span of these containers is over 15 years, if carefully handled. Therefore, polyethylene silo tank and polyethylene drum could be essential for smallholder farmers, as they need to invest once, representing a long-term economic investment. However, both containers may not be practical for storage of a large amount of paddy rice in mill companies, since they cannot be pilled and the withdraw of rice for processing may be time-consuming. Thus, for mill companies, the use of Super Grain Bag and GrainSafe bag may prove the best option, as long as additional measures are taken to control rodents and insects in the warehouse environment.

The initial moisture content of the paddy rice used in this experiment was $11.13 \%$. Although a significant increase was observed after six months of storage in all containers, except GrainSafe bag, the moisture content remained below the safe limit recommended for long-term storage in Mozambique $(\leq 13 \%)$. Hermetic storage containers reduce the interaction between the environment and the stored grain, limiting the variability of grain moisture content if the storage container is properly sealed (Williams et al., 2014; Mutambuki et al., 2019). In contrast, polypropylene bags allow a constant interaction between the grain and the environment until an equilibrium is achieved. Therefore, when the grain is stored in polypropylene bags, fluctuation in moisture content is expected. In this study, the relative humidity in intergranular spaces in all hermetic containers remained stable during the storage period, while fluctuations were recorded in polypropylene bags, which corroborates with previous studies (Ng'ang'a et al., 2016; Lane and Woloshuk, 2017; Capilheira et al., 2019). The polyethylene drum presented the lowest intergranular relative humidity thorough the experiment, which is somehow surprising. No sound explanation can be offered for these differences in relative humidity amongst the hermetic containers, especially considering that all the storage containers were placed in the same environment, the grain used had similar moisture content, and we did not register significant differences in the density of insects amongst the hermetic containers. Nevertheless, we did not find a significant relationship between the grain moisture content in polypropylene bags and the relative humidity in the intergranular spaces ( $\mathrm{r}=0.15, P=0.535$ ).

Findings from this study corroborate with several previous reports analysing the effect of hermetic storage in the grain moisture content. For instance, Prasantha et al. (2014) reported an increase in the moisture content of the paddy rice stored in super grain bags after nine months of storage, although this increase was lower than that recorded in polypropylene bags. Other studies have shown that moisture content of maize grain stored in hermetic containers (such as PICS bags and metal silos) increased in log-term storage while it decreased in polypropylene bags (Williams et al., 2014; Ng'ang'a et al., 2016; Abass et al., 2018). Cellular respiration of insects and grain inside the containers would result in the production of oxygen, water and energy (Murdock et al., 2012). After depletion of oxygen due to respiration, the insect activity and production of water would stop (Abass et al., 2018). Nevertheless, intermittent opening of the containers for grain sampling may have contributed to the fluctuation of the grain moisture content in hermetic containers. In contrast to our findings, Baoua et al. (2016) did not report any significant increase in the moisture content of paddy rice stored in PICS bags for 18 months, whereas fluctuations of grain moisture content occurred in non-hermetic storage containers. The discrepancies in the moisture content behaviour for grain held in hermetic and non-hermetic containers between different studies may be attributed to the differences in the environmental conditions in the experiment sites.

\section{Conclusions}

Hermetic and non-hermetic storage systems did not show differences in the grain moisture content, and in both systems, the moisture content remained within the recommended range for safe storage of paddy rice. The hermetic storage containers reduced the number of live insects and maintained it stable over 12 months of storage, while the traditional polypropylene bags prevented the increase of insect population only in the first three months of storage. Moreover, the hermetic systems minimized damage in grain and kept the weight loss steady over the period under analysis.

The present study suggests that the hermetic containers evaluated can be an alternative to preserve rice grain during 12 months without a need to apply pesticides, reducing the level of grain postharvest losses due to storage insect attack. Polyethylene silo tank presents the additional advantage of having a longer life span when compared to other containers with similar benefits in terms of protecting the grain against insects by inhibiting their multiplication and cross-contamination during storage. This structure can be available in a diverse range of size, from $150 \mathrm{~kg}$ to $750 \mathrm{~kg}$ capacity. Further studies are required to evaluate the effectiveness of hermetic containers under analysis to minimize fungal growth and to maintain the grain germination potential, as many smallholder farmers in sub-Saharan African countries use grain from previous harvests as seed.

\section{Author statement}

Rafael Nguenha: Formal analysis, Conception and design of study, Analysis and/or interpretation of data, Drafting the manuscript, Revising the manuscript critically for important intellectual content. Lucas Tivana: Conceptualization, Conception and design of study. Maria Otilia Carvalho: Conception and design of study, Revising the manuscript critically for important intellectual content. Ana I. Ribeiro-Barros: Conceptualization, Conception and design of study, Revising the manuscript critically for important intellectual content. A. Ndayiragije: Conception and design of study. Gervâncio Covele: Formal analysis, Conceptualization, Conception and design of study, Analysis and/or interpretation of data, Drafting the manuscript, Acquisition of data. Anacleto Gulube: Conceptualization, Conception and design of study, Analysis and/or interpretation of data, Drafting the manuscript, Acquisition of data. Approval of the version of the manuscript to be published (the 
names of all authors must be listed): R. Nguenha, L. Tivana, M.O. Carvalho, A.I. Ribeiro-Barros, A. Ndayiragije, G. Covele, A. Gulube.

\section{Funding}

This work was supported by funds of Camões, Instituto da Cooperação e da Língua, and by Fundação para a Ciência e Tecnologia, Portugal, through the contribution to the International Rice Research Institute, Mozambique, and the research units UID/04129/ 2020 (LEAF), UIDP/04035/2020 (GeoBioTec), and UIDB/00239/2020 (CEF).

\section{Declaration of competing interest}

The authors declare that they have no known competing financial interests or personal relationships that could have appeared to influence the work reported in this paper.

\section{Acknowledgements}

The authors acknowledge Inacio de Sousa Rice Mill company, for the assistance provided to transport the rice paddy from Palmeiras to Umbeluzi Agrarian Research Institute. Sincere thanks are also addressed to Ms Adelia for her valuable support on experiment setup and follow up.

\section{Appendix A. Supplementary data}

Supplementary data to this article can be found online at https://doi.org/10.1016/j.jspr.2020.101710.

\section{References}

Abass, A.B., Fischler, M., Schneider, K., Daudi, S., Gaspar, A., Rüst, J., Kabula, E., Ndunguru, G., Madulu, D., Msola, D., 2018. On-farm comparison of different postharvest storage technologies in a maize farming system of Tanzania Central Corridor. J. Stored Prod. Res. 77, 55-65.

Adams, J., Schulten, G., 1978. Losses caused by insects, mites and microorganism in post harvest grain assessment methods. Association of Cereal Chemstry.

Adhikarinayake, T.B., Palipane, K.B., Müller, J., 2006. Quality change and mass loss of paddy during airtight storage in a ferro-cement bin in Sri Lanka. J. Stored Prod. Res. 42, 377-390.

Baoua, I., Amadou, L., Ousmane, B., Baributsa, D., Murdock, L., 2014. PICS bags for post-harvest storage of maize grain in West Africa. J. Stored Prod. Res. 58, 20-28.

Baoua, I.B., Amadou, L., Bakoye, O., Baributsa, D., Murdock, L.L., 2016. Triple bagging hermetic technology for post-harvest preservation of paddy rice Oryza sativa $\mathrm{L}$. in the Sahel of West Africa. J. Stored Prod. Res. 68, 73-79.

Capilheira, A.F., Cavalcante, J.A., Gadotti, G.I., Bezerra, B.R., Hornke, N.F., Villela, F.A. 2019. Storage of soybean seeds: packaging and modified atmosphere technology. Rev. Bras. Eng. Agrícola Ambient. 23, 876-882.

Chigoverah, A.A., Mvumi, B.M., 2016. Efficacy of metal silos and hermetic bags against stored-maize insect pests under simulated smallholder farmer conditions. J. Stored Prod. Res. 69, 179-189.

De Groote, H., Kimenju, S.C., Likhayo, P., Kanampiu, F., Tefera, T., Hellin, J., 2013. Effectiveness of hermetic systems in controlling maize storage pests in Kenya. J. Stored Prod. Res. 53, 27-36.

García-Lara, S., Ortiz-Islas, S., Villers, P., 2013. Portable hermetic storage bag resistant to Prostephanus truncatus, Rhyzopertha Dominica, and Callosobruchus maculatus. J. Stored Prod. Res. 54, 23-25.

Groote, H., Kimenju, S., Likhayo, P., Kanampiu, F., Tefera, T., Hellin, J., 2013. Effectiveness of hermetic systems in controlling maize storage pests in Kenya. J. Stored Prod. Res. 53, 27-36.

Guenha, R., Salvador, B.D.V., Rickman, J., Goulao, L.F., Muocha, I.M., Carvalho, M.O., 2014. Hermetic storage with plastic sealing to reduce insect infestation and secure paddy seed quality: a powerful strategy for rice farmers in Mozambique. J. Stored Prod. Res. 59, 275-281.

Hashem, Reichmuth, C.H., 1994. Interactive effects of high carbon dioxide or lowoxygen atmospheres and temperature on hatchability of eggs of three storedproduct moths. J. Plant Dis. Prot. 178-182.

Hashem, M.Y., Ismail, I.I., Lutfallah, A.F., El-Rahman, S.F.A., 2014. Effects of carbon dioxide on Sitotroga cerealella (Olivier) larvae and their enzyme activity. J. Stored Prod. Res. 59, 17-23.
Hell, K., Edoh Ognakossan, K., Lamboni, Y., 2014. PICS hermetic storage bags ineffective in controlling infestations of Prostephanus truncatus and Dinoderus spp. in traditional cassava chips. J. Stored Prod. Res. 58, 53-58.

Kajisa, K., Payongayong, E., 2011. Potential of and constraints to the rice Green Revolution in Mozambique: a case study of the Chokwe irrigation scheme. Food Pol. 36, 614-625.

Kalsa, K.K., Subramanyam, B., Demissie, G., Mahroof, R., Worku, A., Gabbiye, N., 2019. Evaluation of postharvest preservation strategies for stored wheat seed in Ethiopia. J. Stored Prod. Res. 81, 53-61.

Kumar, D., Kalita, P., 2017. Reducing postharvest losses during storage of grain crops to strengthen food security in developing countries. Foods 6.

Lane, B., Woloshuk, C., 2017. Impact of storage environment on the efficacy of hermetic storage bags. J. Stored Prod. Res. 72, 83-89.

Lêda, R.A.F., Ernandes, R.d.A., Juliana, L.P., André, R.D.C., Rafaela, C.C.R., 2009. Armazenamento de soja em silos tipo bolsa. Eng. Agrícola 29, 91-100.

Li, L., Arbogast, R.T., 1991. The effect of grain breakage on fecundity, development, survival, and population increase in maize of Tribolium castaneum (Herbst) (Coleoptera: Tenebrionidae). J. Stored Prod. Res. 27, 87-94.

Likhayo, P., Bruce, A., Tefera, T., 2016. On-Farm evaluation of hermetic technology against maize storage pests in Kenya. J. Econ. Entomol. 109, 1943-1950.

Matule, E.D., Macarringue, L.S., 2020. Assessment of soil loss to vulnerability in the Boane District in Mozambique. Sociedade \& Natureza 32, 211-221.

Milani, J.M., 2013. Ecological conditions affecting mycotoxin production in cereals: a review. Vet. Med. 58, 405-411.

Moçambique, B.d., 2019. O Agronegócio como Factor de Dinamização da Economia: O Caso da Cadeia de Valor do Arroz na Província de Gaza. Banco de Moçambique, Xai-Xai, Gaza, p. 37.

Moreno-Martinez, E., Jiménez, S., Vázquez, M.E., 2000. Effect of Sitophilus zeamais and Aspergillus chevalieri on the oxygen level in maize stored hermetically. J. Stored Prod. Res. 36, 25-36.

Murdock, L.L., Margam, V., Baoua, I., Balfe, S., Shade, R.E., 2012. Death by desiccation: effects of hermetic storage on cowpea bruchids. J. Stored Prod. Res. 49, $166-170$.

Mutambuki, K., Affognon, H., Likhayo, P. Baributsa, D., 2019. Evaluation of Purdue Improved Crop Storage Triple Layer Hermetic Storage Bag against Prostephanus Truncatus (Horn) (Coleoptera: Bostrichidae) and Sitophilus Zeamais (Motsch.) (Coleoptera: Curculionidae). Insects 10.

Nadeem, S., Hamed, M., Shafique, M., 2011. Feeding preference and developmental period of some storage insect species in rice products. Pakistan J. Zool. 43, 79-83.

Nansen, C., Flinn, P., Hagstrum, D., Toews, M.D., Meikle, W.G., 2009. Interspecific associations among stored-grain beetles. J. Stored Prod. Res. 45, 254-260.

Navarro, S., 2012. The use of modified and controlled atmospheres for the disinfestation of stored products. J. Pest. Sci. 85, 301-322.

Ng'ang'a, J., Mutungi, C., Imathiu, S., Affognon, H., 2016. Effect of triple-layer hermetic bagging on mould infection and aflatoxin contamination of maize during multi-month on-farm storage in Kenya. J. Stored Prod. Res. 69, 119-128.

Ng'ang'a, J., Mutungi, C., Imathiu, S.M., Affognon, H., 2016. Low permeability triplelayer plastic bags prevent losses of maize caused by insects in rural on-farm stores. Food security 8, 621-633.

Njoroge, A.W., Affognon, H.D., Mutungi, C.M., Manono, J., Lamuka, P.O. Murdock, L.L., 2014. Triple bag hermetic storage delivers a lethal punch to Prostephanus truncatus (Horn) (Coleoptera: Bostrichidae) in stored maize. J. Stored Prod. Res. 58, 12-19.

Phophi, M.M., Mafongoya, P., Lottering, S., 2020. Perceptions of climate change and drivers of insect pest outbreaks in vegetable crops in limpopo province of South Africa. Climate 8, 27.

Pires, E., Nogueira, R., 2018. Damage caused by Rhyzopertha dominica (Fabricius, 1792)(Coleoptera: Bostrichidae) in stored Brazil nuts. Scientific Electronic Archives $11,57-61$.

Prasad, R., Shivay, Y.S., Kumar, D., 2014. Agronomic biofortification of cereal grains with iron and zinc-chapter two. Adv. Agron. 125, 55-91.

Prasantha, B.D.R., Hafeel, R.F., Wimalasiri, K.M.S., Pathirana, U.P.D., 2014. End-use quality characteristics of hermetically stored paddy. J. Stored Prod. Res. 59, $158-166$.

Sanon, A., Dabiré-Binso, L.C., Ba, N.M., 2011. Triple-bagging of cowpeas within high density polyethylene bags to control the cowpea beetle Callosobruchus maculatus F. (Coleoptera: bruchidae). J. Stored Prod. Res. 47, 210-215.

Silva, V., Mol, H.G., Zomer, P., Tienstra, M., Ritsema, C.J., Geissen, V., 2019. Pesticide residues in European agricultural soils-A hidden reality unfolded. Sci. Total Environ. 653, 1532-1545.

Tandane, D.R., 2015. Avaliação do papel do extensionista rural no desenvolvimento das actividades agrícolas para a segurança alimentar nas comunidades do distrito de boane: caso da cooperativa 25 de setembro no distrito de boane. Universidade Eduardo Mondlane.

Tapondjou, L.A., Adler, C., Bouda, H., Fontem, D.A., 2002. Efficacy of powder and essential oil from Chenopodium ambrosioides leaves as post-harvest grain protectants against six-stored product beetles. J. Stored Prod. Res. 38, 395-402.

Tefera, A., Teshome, A., Singano, C., 2018. Effectiveness of improved hermetic storage structures against maize storage insect pests Sitophilus zeamais and prostephanus truncatus. J. Agric. Sci. 10, 100-106.

Tefera, T., Kanampiu, F., De Groote, H., Hellin, J., Mugo, S., Kimenju, S., Beyene, Y Boddupalli, P.M., Shiferaw, B., Banziger, M., 2011a. The metal silo: an effective grain storage technology for reducing post-harvest insect and pathogen losses in maize while improving smallholder farmers' food security in developing 
countries. Crop Protect. 30, 240-245.

Tefera, T. Mugo, S., Likhayo, P., 2011b. Effects of insect population density an storage time on grain damage and weight loss in maize due to the maize weevil Sitophilus zeamais and the larger grain borer Prostephanus truncatus. Afr. J Agric. Res. 6, 2249-2254.

Togola, A., Seck, P., Glitho, I., Diagne, A., Adda, C., Toure, A., Nwilene, F., 2013. Economic losses from insect pest infestation on rice stored on-farm in Benin. J. Appl. Sci. 13, 278-285.

Trematerra, P. Paula, M.C.Z. Sciarretta, A., Lazzari, S.M.N., 2004. Spatio-tempora analysis of insect pests infesting a paddy rice storage facility. Neotrop. Entomol. 33, 469-479.

Tsujimoto, Y., Rakotoson, T., Tanaka, A., Saito, K., 2019. Challenges and opportunities for improving $\mathrm{N}$ use efficiency for rice production in sub-Saharan Africa. Plant Prod. Sci. 22, 413-427.

Van Dyck, H., Bonte, D., Puls, R., Gotthard, K., Maes, D., 2015. The lost generation hypothesis: could climate change drive ectotherms into a developmental trap? Oikos 124, 54-61.

Villers, P., Bruin, T.D., Navarro, S., 2006. Development and applications of the hermetic storage technology. In: Proceedings of the 9th International Working Conference on Stored-Product Protection, ABRAPOS, Passo Fundo, RS, Brazil, 1518 October 2006. Brazilian Post-Harvest Association (ABRAPOS), pp. 719-729.

Villers, P., Navarro, S., DeBruin, T., 2008. Development of hermetic storage technology in sealed flexible storage structures. In: Proceedings of the 8th International Conference on Controlled Atmosphere and Fumigation in Stored Products. CAF, pp. 21-26.

Walker, S., Jaime, R., Kagot, V., Probst, C., 2018. Comparative effects of hermetic and traditional storage devices on maize grain: mycotoxin development, insect infestation and grain quality. J. Stored Prod. Res. 77, 34-44.

Waongo, A., Traore, F., Ba, M.N., Dabire-Binso, C., Murdock, L.L., Baributsa, D., Sanon, A., 2019. Effects of PICS bags on insect pests of sorghum during longterm storage in Burkina Faso. J. Stored Prod. Res. 83, 261-266.

Webley, D., 1985. Manual of Pest Control for Food Security Reserve Grain Stocks, Chinese ed. Rome.

Williams, S.B., Baributsa, D., Woloshuk, C., 2014. Assessing Purdue Improved Crop Storage (PICS) bags to mitigate fungal growth and aflatoxin contamination. J. Stored Prod. Res. 59, 190-196. 